\title{
Life is sexually transmitted: Live with it
}

T he truism 'life is sexually transmitted' has been passed around the globe from PC to PC via the Internet. Whether such messages contain a virus, and how well protected the computer is with a virus scan, firewall or a pop-up blocker is a concern.

Sex, like surfing the Internet, is full of wonderful potential, but protection from viruses and worms is likewise important. The technology of protection-like safer Internet surfing-is available, but people often need help to understand how and why to use it-hence the need for professionals such as practice nurses who are skilled and knowledgeable in health promotion. And sex is everyone's concern: although young people generally do it more, older people do it too.

This article explores issues of sexual health relevant to client care that is, could, or should be offered by nurses in general practice. Sexual health is often the most important element of a person's holistic health and wellbeing to be overlooked during consultations. Sadly, some professional carers consider it is not their job, is too embarrassing, morally 'problematic' or outside their area of expertise. Sexual health is part of life: not to address it means that health professionals fail to fully address all aspects of their clients' holistic health and wellbeing. The result is selective or reduced—not holistic—care. This article will point to ways for practice nurses to remedy this situation.

\section{Proactive sexual health care}

A key question is should practice nurses wait for the client to mention problems about sexual health first, or should they address sexual health matters pre-emptively? Some nurses and other health professionals might prefer to wait until the client mentions an issue first (Holland et al, 1996; Hekkink et al, 2005), but research shows that clients often live in hope that it will be the health professional who makes the first move (Tomlinson, 1999; Men's Health Forum, 2003).

To wait for the client to mention it can help deepen the perception that holistic sexual health is all about sexual ill-health. Because of statistics on sexual infections, 'teenage pregnancy' and abortion, sexual health is often perceived to be solely to do with infections and unplanned or teenage conceptions (Evans, 2004a). But sexual health, as part of holistic care, is much wider than that.

Consider the client with low self-esteem, who does not want to use condoms because she simply does not think she is worthy of anyone taking care of her; or the young boy who is gay, being bullied at school for it, and now self-harming, including being vulnerable to sexual abuse and infections; or the man with cardiac problems and unable to get an erection because of the medication, but so desperate to hold on to his new partner and have meaningful sex.

Or there was the case of the post-menopausal woman who was so frightened at her cervical smear test, her thighs rigid, that the practice nurse was unhappy at the smear and threatened she might have to do it again. The woman's daughter shouted, 'You should have told her, Mum: you haven't had sex for years!' All anecdotal evidence, but clearly part of the repertoire of experiential learning for practice nurses and many of their clients.

\section{The need for health promotion}

The consequences of not proactively addressing sexual health with clients can often be sexual ill-health that might have been prevented (Medical Foundation for AIDS and Sexual Health, 2005). Like having an effective virus scan and firewall on a PC, practising safer sex, for example, by using barrier methods of protection such as condoms can effectively prevent undesirable consequences of sex. In June 2006, research results confirmed that proper use of condoms effectively reduces transmission of the human papillomavirus (HPV), the cause of genital warts, which, for some people can be a predisposition towards cervical and anal cancers (Horn, 2006; Winer et al, 2006).

A new vaccine against HPV has now been successfully developed, which, in the future, could greatly reduce the numbers of people with cervical, and potentially, anorectal cancers (Centers for Disease Control and Prevention, 2006).
David T Evans

argues that practice

nurses have a duty

to prepare

themselves to

provide proactive

sexual health advice

as part of their role

in holistic health

care

David T Evans is Educational consultant in sexual health (freelance) and doctoral research student in education, University of Greenwich

Submitted for peer review 25 July 2006; accepted for publication 28 July 2006

Key words: Condoms, duty of care, holistic care, prophylaxis, safer sex, sexual health, sexual infections 


\section{Prophylaxis in the heat}

Many practice nurses will be advising clients on how not to suffer the damaging effects of sun this summer, with safer sunning, safer tanning (even safer surfing for those so adventurous). But while it is straightforward to recommend covering up with sun lotion, covering up using a condom to prevent some of those other preventable issues that go hand-in-hand with the heat of summer is often left unmentioned.

Durex has launched a summer-long national campaign, called 'He Says, You Say', with resources for health professionals (Figure 1). Such campaigns do not routinely target everyone at the same time. This campaign is geared towards young females who have sex with males. Needless to say, other campaigns might focus on safer sex for same sex partners, specific issues for older people, people with disabilities or conditions that make them sexually vulnerable or feeling non-sexually attractive.

\section{Preparing practice nursing}

Since so many people potentially want or need to talk about sexual health, practice nurses need to prepare themselves with the knowledge and skills to appropriately address these issues as part of their client's holistic care. It is therefore important to consider whether practice nurses are prepared to match the requirements of level 1 sexual health service provision set by the Department

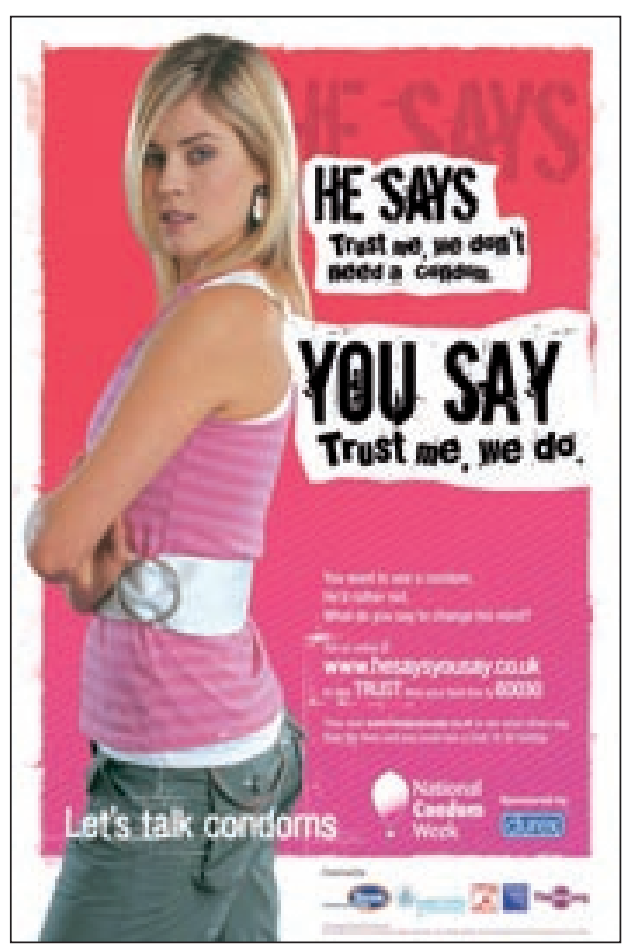

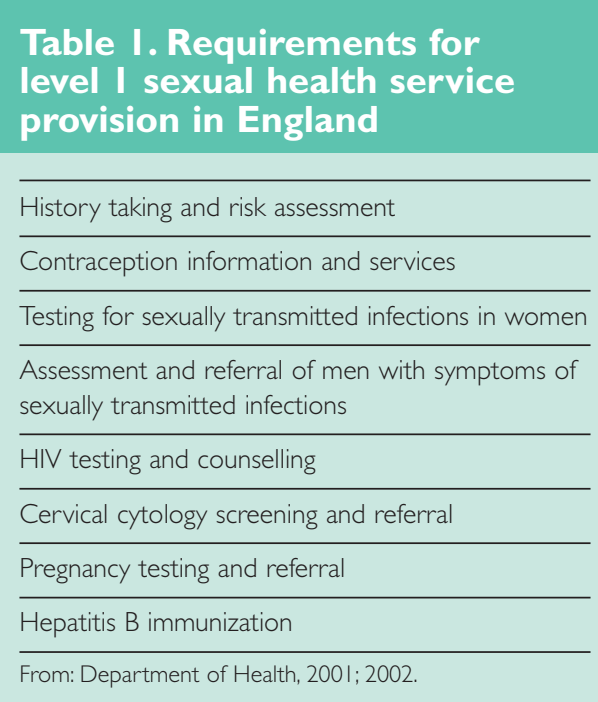

of Health (DH) in England (DH, 2001; 2002a) (Table 1). Equivalent strategies have been published for Scotland and Wales (the Northern Ireland strategy is awaiting ratification) (Miles, 2006). The Scottish and Welsh strategies take a wider, more holistic approach to sex and relationships, rather then simply setting epidemiological targets, as the DH has in England did. If the Scottish and Welsh strategies are put into effect, they can be expected to achieve the aims of the $\mathrm{DH}$ document without setting them as targets.

\section{Sexual health competencies}

Many practice nurses are already competent, confident and well accomplished in matters of sexual health, including the requirements of level 1 services (Royal College of Nursing (RCN), 2004). Many have a wealth of experiential learning, as well as appropriate professional and academic qualifications in aspects of sexual health, such as contraception and reproductive health care, HIV and genitourinary infections. But many sexual health issues encountered in giving holistic care are wider than these matters, which is why the level 1 service requirements need to be underpinned with accurate and appropriate sexual health assessments customized to each individual. The DH (2002b) asserts that:

[PCTs] will want to ensure a focus on prevention services as well as treatment, to forge local partnerships to more effectively address health inequalities and ensure an appropriate balance between investment in primary and community services as well as acute. 


\section{Examples in practice}

A practical example of including level 1 service requirements is responsibility for HIV testing and counselling. The $\mathrm{DH}$ requires nurses and certain other health professionals to be knowledgeable and skilled to effectively provide HIV pre-test discussion (DH, 1996). However, there would be many patients or clients who might be concerned about the use of such sensitive and confidential information. The British Medical Association (BMA) and Association of British Insurers (ABI) (2002) have jointly agreed that only a positive HIV antibody result is the business of the insurance industry; not, as in previous times, simply testing or counselling for HIV, hepatitis B or any other sexual infection.

It is equally important to know that the BMA/ABI guidelines (2002) show that the patient's sexual orientation is of no business of the insurance industry. After years of fear and mistrust by many non-heterosexual people toward the insurance industries and the health-care providers who might furnish them with such information, a lot of work remains to be done in general practice to convince this constituency of clients of the new boundaries of trust and confidentiality (Keogh et al, 2004). Nurses have a duty to give clear and accurate information on these requirements and responsibilities (RCN, 2001; 2006).

Other HIV issues relevant to practice nurses include:

口 Working to eliminate HIV stigma and discrimination, now covered under the Disability Discrimination Act (2005) (International Council of Nurses, 2003; National AIDS Trust, 2004)

Establishing a practice policy for treating a transgender person who is HIV positive (Schilder et al, 1998)

( Agreeing appropriate advice about safer sex for two newly diagnosed HIV-positive partners

I Informing practice staff about where the resources for the urgent administration of post-exposure prophylaxis (PEP) after sexual risk of HIV transmission are kept in the locality (Community HIV and AIDS Prevention Service, 2004; Evans, 2005).

It is important to know that, despite accusations to the contrary, the provision of PEP does not increase episodes of unprotected sex (Carter, 2004; Martin et al, 2004).
These are issues practice nurses need to understand, as well as having the appropriate skills to deal with such sensitive and worrying issues in a person's life, even if only to effectively refe a client to another service provider.

\section{A problematic threesome}

Three other problems make the role of an informed and skilled nurse in giving sexual health advice even more important:

- The large percentage of males in society with poor use of preventive (sexual) health services

[ Poor availability of good quality, free condoms

口 The general lack of availability and ready access to sexual health service provision for when things go wrong.

\section{Calling all men}

The topic of males and preventive (sexual) health has been addressed by many authors, including the important Men's Health Forum report (2003). For generations health professionals have bemoaned men's failure to deal proactively with their own health, be this because of personal, cultural or gender-specific expectations, including hyper-masculinized ('macho') identities (Evans, 2004b). Yet a large part of health care continues to fail these men, by reproducing the same service patterns that are regularly not attended by many males. The DH (2002a) encourages a reversal in this trend by offering non-traditional approaches to health promotion and service delivery, for example, through proactive outreach, and meeting these men 'where they are at'.

\section{Condoms: 'He says, you say'}

Many problems regarding condom use are through human error or dislike. They are often used only as contraception instead of contra-infection, they are not easily, freely and readily available to many males, and there continues to be cultural and sometimes religious barriers to their use (Evans, 2004a; Hatherall et al, 2005).

The 2006 Durex campaign focuses on empowering young women to use condoms in the face of reluctance to use them by their male partners. 'He Says You Say' is an Internet resource aimed at helping young women and young men explore a number of issues, barriers and problems that lead to lit- 
tle or no condom use, and hence a predisposition to the preventable consequences of unprotected sexual intercourse, such as infections and unplanned or unwanted conceptions (Metcalfe, 2004).

Practice nurses can play an important role in improving the provision, uptake and use of condoms, not least, by advocating greater access to free and easy supplies, for example, at all first-access health services, as advocated by the World Health Organization and Joint United Nations Programme on HIV/AIDS (1997). Such services include practice settings, travel clinics and outreach services provided locally through school nursing, midwifery, health visiting and other young people's services. Practice nurses require accurate knowledge and skills to adapt and convey the message that condoms are a 'contra-infective' safer sex measure. They should also be able to demonstrate their use appropriately to their individual clients' needs and understanding.

Some practice nurses may be averse to promoting greater and more effective condom use. One reason for this may be faith (Fee, 2001). Condoms4Life, a campaign sponsored by Catholics for a Free Choice, explores many implications of this, offering some alternative thoughts on this routine issue (Condoms4Life, 2003).

Evans (2006) asserts that prophylactic (sexual) health care is an obligation of nurses, a duty of care, which individual nurses and their practices need to explore and resolve adequately, to the patient's benefit when individual carers have moral objections. The client should not end up as a patient with sexual ill-health because of a health professional's personal beliefs.

\section{Table 2. Education resources}

\begin{tabular}{l} 
Royal College of Nursing \\
More information on the RCN Sexual Health Skills \\
distance learning course, and the University of \\
Greenwich's new collaborative e-learning \\
Promoting Sexual Health module can be seen at \\
www.rcn.org.uk/sexualhealthlearning \\
\hline Genito-Urinary Nurses Association (GUNA) \\
GUNA promotes education and networking for \\
nurses working in the field of genitourinary \\
medicine. It hosts two clinical meetings a year and \\
produces practice guidelines and sample protocols, \\
as well band specific Knowledge and Skills \\
Framework profiles for nurses working in \\
genitourinary and sexual health care \\
www.guna.org.uk
\end{tabular}

\section{Improving service provision}

Adequate service provision in sexual health promotion and ill-health prevention is a resource issue with political and social implications. Providing easier, free access to condoms and hepatitis B (and hepatitis A) vaccines for those who are sexually vulnerable is expensive. Yet, from a financial perspective alone, prophylaxis is the least expensive option for a society faced with escalating numbers of people with the ill-health consequences of unprotected sexual intercourse (House of Commons Health Committee, 2003).

Poor sexual health includes short-term costs, such as treating infections or providing abortions. The longer term implications include the ongoing costs resulting from unplanned and unwanted conceptions and secondary (and tertiary) complications of sexual infections such as pelvic inflammatory disease, infertility, and chronic ill-health: hepatitis, HIV, secondary and, potentially, tertiary syphilis.

\section{A knowledge and skills framework} An unprecedented innovation in developing knowledge and skills for nurses in sexual health aspects of care is the RCN's Sexual Health Skills distance learning course (Table 2). This double module has attracted more practice nurses than any other sexual health course in the 2 years since its inauguration. Practice nurses have evaluated it favourably, with clear examples of how the learning is developing them personally as well as professionally, and improving their skills and the provision of general practice services. One important improvement has been in understanding the wider implications of sexual health stigmas, and, most significantly, in their skills at challenging and overcoming these, in line with the aims of national and RCN (2001) sexual health strategies.

\section{Conclusions}

Sexual health is a foundational element of life and holistic care. Practice nurses are instrumental in effectively promoting sexual health. They can help promote the use of preventive measures which can reduce the incidence of sexually transmitted infections and preventable episodes of sexual ill-health. Practice nurses could also become more actively involved in greater promotion of condoms as a form of contra-infection (as well as contraception).

There are a number of barriers to more effective sexual health care. More resources 
for education for health professionals, including practice nurses, to develop the necessary knowledge and skills to complement client needs and service provision in sexual health are required. In addition, resources are needed to provide better and freer access to condoms, and to health services to help people when preventive measures fail.

For improving the sexual health of clients, practice nurses are encouraged to seek the types of learning that can help them help others to prevent undesirable consequences of sex, efficiently deal with the management of particular instances of sexual ill-health, and actively challenge the occurrence sexual health-related stigmas.

This article is based on a presentation made by the author to the 2006 RCN Practice Nurse Conference, Sopwell House, St Alban's, Hertfordshire, 5-7 July.

\section{References}

British Medical Association, Association of British Insurers (2002) Medical Information and Insurance. Joint guidelines from the British Medical Association and the Association of British Insurers. BMA, London. www.abi.org.uk/Display/File/364/ BlueBook.pdf (accessed 27 July 2006)

Carter M (2004). PEP for sexual exposure to HIV doesn't lead to more risky sex, AIDSMAP news, 06 April 2004, cited at: www.aidsmap.org/en/news cited on: 11.10 .04

Centers for Disease Control and Prevention (2006) Merck cervical cancer vaccine cleared for use in girls, women. 9 June. www.thebody.com/cdc/news updates archive/2006/jun9 06/gardasil. html?m154h (accessed 27 July 2006)

Community HIV and AIDS Prevention Service (2004) Post-exposure prophylaxis. Terrence Higgins Trust, London

Condoms4Life (2003) Sex in the HIV/AIDS era. Catholics for a Free Choice. www.condoms4life. org/facts/index.htm\# (accessed 27 July 2006)

Department of Health (1996) Guidelines for pre-test discussion on HIV testing. March. www.advisorybodies.doh.gov.uk/eaga/guidelineshivtestdiscuss.pdf (accessed 27 July 2006)

Department of Health (2001) The National Strategy for Sexual Health and HIV. The Stationery Office London

Department of Health (2002a) The National Strategy for Sexual Health and HIV: Implementation Action Plan. The Stationery Office London

Department of Health (2002b) Securing service delivery: Commissioning freedoms of primary care trusts. Health service circular HSC 2002/007. DH, London

Evans DT (2004a) Behind the headlines: Sexual health implications for nursing ethics and practice. Primary Health Care Journal 14(8): 40-9

Evans DT (2004b) The trouble with men is ... Raising the profile of men's sexual health. Nursing in Practice Journal 2004(17): 36-8

Evans DT (2005) Sex, drugs and HIV prevention: A case for PEPSE. Nursing in Practice Journal March/ April: 54-7

Evans DT (2006) Promoting sexual health to young people to reduce STIs. Nursing Times 102(30): 25-6
Fee E (1999) The wages of sin. Lancet 354(Suppl): SIV61

Hatherall BN, Stone N, Ingham R, McEachran J (2005) The Choreography of Condom Use: How, Not Just If, Young People Use Condoms. A report prepared for Brook by The Centre for Sexual Health Research, University of Southampton

Hekkink CF, Wigersma L, Yzermans CJ, Bindels PJE (2005) HIV nursing consultants: Patients' preferences and experiences about the quality of care. Journal of Clinical Nursing 14(3): 327-33

Holland J, Ramazanoglu C, Scott S, Sharpe S, Thomson R (1996) 'Don't die of ignorance'. I nearly died of embarrassment: Condoms in context. In: Jackson S, Scott, S, eds. Feminism and Sexuality: A Reader. Edinburgh University Press, Edinburgh: 117-29

Horn T (2006) Lucky latex: Condoms protect against HPV too. www.aidsmeds.com/news/am20060622. html (accessed 27 July 2006)

House of Commons Health Committee (2003) Select Committee on Health. Third report. Session 2002 03. The Stationery Office, London. www.publications.parliament.uk/pa/cm200203/cmselect/ cmhealth/69/6902.htm (accessed 27 July 2006)

International Council of Nurses (2003) Nurses: Fighting AIDS Stigma, Caring for All. ICN, Geneva

Keogh P, Weatherburn P, Henderson L, Reid D, Dodds C, Hickson F (2004) Doctoring gay men: Exploring the contribution to general practice. Research report. Sigma Research, London: 58

Martin JN, Roland ME, Neilands TB et al (2004) Use of postexposure prophylaxis against HIV infection following sexual exposure does not lead to increases in high-risk behavior. AIDS 18(5): 787-92

Medical Foundation for AIDS and Sexual Health (2005) Recommended Standards for Sexual Health Services. Medical Foundation for AIDS and Sexual Health, London

Metcalfe T (2004) Sexual health: Meeting adolescents' needs. Nurs Stand 18(46): 40-3

Men's Health Forum (2003) Private Parts, Public Policy: Improving Men's Sexual Health. MHF, London

Miles K (2006) Putting STI screening on the primary care nursing agenda. Nurs Stand 16(1): 31-3

National AIDS Trust (2004) HIV-related stigma and discrimination. Impact (Policy Bulletin) 9. National AIDS Trust, London

Royal College of Nursing (2001) RCN sexual health strategy: Guidance for nursing staff. RCN, London: 28

Royal College of Nursing (2004) Sexual Health Competencies: An integrated career and competency framework for sexual and reproductive health nursing. RCN, London

Royal College of Nursing (2006) Lesbian, gay, bisexual and transgender patients or clients. Guidance for nursing staff on next-of-kin issues. April. RCN, London

Schilder AJ, Laframboise S, Hogg RS, Trussler T, Goldstone I, Schechter MT, O'Shaughnessy MV (1998) 'They Don't See Our Feelings': The health care experiences of HIV-positive transgendered persons. J Gay Lesbian Med Assoc 2(3): 103-12

Tomlinson J, ed (1999) ABC of Sexual Health. BMJ Books, London

World Health Organization, The Joint United Nations Programme on HIV/AIDS (UNAIDS) (1997) Sexually Transmitted Diseases: Policies and Principles for Prevention and Care. WHO, Geneva

Winer RL, Hughes JP, Feng Q, O'Reilly S, Kiviat NB, Holmes KK, Koutsky LA (2006) Condom use and the risk of genital human papillomavirus infection in young women. N Engl J Med 354(25): 2645-54

\section{KEY POINTS}

․ It is essential for practice nurses to understand the need to be proactive in sexual health matters for their clients

口 Practice nurses need to appreciate the relevance of being as knowledgeable and skilled in sexual health matters as they are in other areas of holistic care

[ Practice nurses could identify opportunities for developing their sexual health knowledge, skills and clinical practice

\section{Conflict of interest:}

None 